\title{
TRABALHO, VIDA SOCIAL E CAPITAL NA VIRADA DO MILÊNIO: APONTAMENTOS DE INTERPRETAÇÃO
}

\author{
Paulo Sergio Tumolo*
}

\begin{abstract}
RESUMO: O presente texto tem como objetivo contribuir com algumas reflexões sobre determinadas características fundantes do atual padrão de acumulação de capital. Para tanto, analisa o processo histórico segundo o qual a subsunção formal do trabalho ao capital, expressa pela extração da mais-valia absoluta, criou a necessidade e as condiçôes para a diminuição do valor da força de trabalho e, por isso, para a produção da mais-valia relativa, que exigia a subsunção real do trabalho ao capital, materializada pelo controle do processo de trabalho e que, por sua vez, implicou, contraditoriamente, a redução do preço da força de trabalho abaixo de seu valor. De forma potencializada, este fenômeno, aliado ao domínio do capital sobre praticamente todas as atividades humanas, resultou, na contemporaneidade, numa subsunção da vida dos trabalhadores ao capital, ou melhor, numa subsunção real da vida social ao capital.
\end{abstract}

Palavras-chave: Subsunção formal do trabalho. Subsunção real do trabalho. Subsunção real da vida social. Mais-valia absoluta. Mais-valia relativa.

\section{WORK, SOCIAL LIFE AND CAPITAL AT THE TURN OF MILLENNIUM: INTERPRETATION NOTES}

ABSTRACT: This paper aims at contributing to some reflections upon the founding features of the current capital accumulation patterns. It thus analyzes the historical process in which the formal subsumption of labor under capital, expressed through the extraction of absolute surplus value, set the stage and conditions to decrease the value of workforce and, hence, produce relative surplus

Professor adjunto do Centro de Ciências da Educação e do Programa de Pós-Graduação em Educação da Universidade Federal de Santa Catarina (UFSC).E-mail: tumolo@ced.ufsc.br 
value. The latter required the real subsumption of work under capital, materialized by the work process control which, in turn, paradoxically entailed a reduction of the price of the workforce. In an exponential way, this phenomenon, in addition to capital taking over almost all human activities, nowadays resulted in a real subjection of the workers' lives to the capital, that is, in a real subsumption of social life under capital.

Key words: Formal/real subsumption of work under capital. Real subsumption of social life under capital. Absolute/relative surplus value

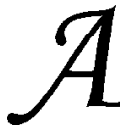

compreensão do atual padrão de acumulação de capital, sobretudo por intermédio da recente reestruturação produtiva e de suas respectivas transformações no mundo do trabalho, tem sido o alvo de inúmeros estudiosos de áreas do conhecimento afins. Muito embora haja uma razoável produção teórica a respeito de tal matéria, ${ }^{1}$ é mister reconhecer que ainda estamos muito distantes de alcançar um patamar satisfatório de apreensão deste fenômeno, não só pela sua contemporaneidade, mas principalmente pelo seu alto grau de complexidade, o que exige um contínuo esforço investigativo. Por causa disso, e dentro desse espírito, o presente texto, longe de apresentar um exame totalmente satisfatório, pretende tão-somente contribuir com algumas reflexões sobre determinadas características fundantes do atual padrão de acumulação de capital, balizadas na análise desenvolvida por Marx em sua crítica da economia política, particularmente em $O$ capital.

Divisão manufatureira e divisão social do trabalho no capitalismo A seção IV de $O$ capital de Marx oferece-nos não só um minucioso estudo sobre os processos de trabalho que foram sendo implementados pelo capital desde a cooperação simples à grande indústria, mas também pistas para a compreensão dos elementos constituintes do movimento do capital, de suas metamorfoses e, portanto, da configuração dos diversos padrões de acumulação, inclusive o atual, que começa a tomar feição por volta do início dos anos 70 do século XX. Um dos temas examinados pelo autor nessa seção é a relação entre a divisão manufatureira do trabalho e a divisão social do trabalho, tendo em vista que tal relação "constitui a base geral de toda produção de mercadorias" (Marx, 1983, p. 277). Historicizando a análise, Marx entende que a divisão do trabalho no interior da sociedade capitalista é mediada pela compra e venda de mercadorias de diferentes ramos de trabalho, ao passo que a divisão manufatureira é mediada pela venda de diferentes forças de trabalho ao mesmo capitalista, que as emprega como força de trabalho combinada. 
A primeira pressupõe o fracionamento dos meios de produção e implica o confronto de produtores independentes de mercadorias, "que não reconhecem nenhuma autoridade senão a da concorrência”, ao passo que a segunda pressupõe a concentração dos meios de produção nas mãos de um capitalista e, ao mesmo tempo, a autoridade incondicional deste sobre o conjunto dos trabalhadores, dos quais comprou a força de trabalho. No modo de produção capitalista, portanto, "a anarquia da divisão social do trabalho e o despotismo da divisão manufatureira do trabalho se condicionam reciprocamente" (idem, ibid., p. 280).

Grosso modo, Marx busca explicitar o significado de duas relaçôes e da relação que elas estabelecem. A primeira diz respeito à relação de confronto, ou melhor, de concorrência que os capitalistas estabelecem entre si, e a segunda corresponde à relação que os capitalistas estabelecem com os trabalhadores. Por causa da concorrência, os capitalistas são constrangidos a buscar diminuir, constantemente, o valor das mercadorias das quais são proprietários, o que só pode ser conseguido por intermédio de mudanças nos processos de trabalho que resultem num aumento da produtividade, quer dizer, na produção de uma quantidade cada vez maior de valores de uso com uma massa menor de valor, que redunda na diminuição do valor unitário das mercadorias. Tendo em vista a importância fulcral dos processos de trabalho, o êxito de tal empreendimento só pode ser alcançado mediante um rigoroso controle dos capitalistas sobre os processos de trabalho e, por conseguinte, da força de trabalho, o que o autor denomina, apropriadamente, de "despotismo da divisão manufatureira de trabalho". Tal controle passa a ser, portanto, o principal elo de conexão com a segunda relação, sobre a qual é preciso discorrer com mais atenção.

A relação entre o capitalista e o trabalhador é estabelecida pela venda e compra da força de trabalho, mediada pelo valor desta mercadoria.

O valor da força de trabalho, como o de toda outra mercadoria, é determinado pelo tempo de trabalho necessário à produção, portanto também reprodução, desse artigo específico. Enquanto valor, a própria força de trabalho representa apenas determinado quantum de trabalho social médio nela objetivado. A força de trabalho só existe como disposição do indivíduo vivo. Sua produção pressupõe, portanto, a existência dele. Dada a existência do indivíduo, a produção da força de trabalho consiste em sua própria reprodução ou manutenção. Para sua manutenção, o indivíduo vivo precisa de certa soma de meios de subsistência. $\mathrm{O}$ tempo de trabalho necessário à produção desses meios de subsistência ou o valor da foça de trabalho é o valor 
dos meios de subsistência necessários à manutenção do seu possuidor (...). A soma dos meios de subsistência deve, pois, ser suficiente para manter o indivíduo trabalhador como indivíduo trabalhador em seu estado de vida normal (...). Em antítese às outras mercadorias, a determinação do valor da força de trabalho contém, por conseguinte, um elemento histórico e moral. (Marx, 1983, p. 141)

Mas como a força de trabalho precisa ser continuamente substituída, tendo em vista que seu proprietário é mortal, a produção e a reprodução da força de trabalho pressupõem a produção e reprodução da vida de seus filhos, vale dizer, de sua família. O valor da força de trabalho, pois, corresponde a um determinado quantum de trabalho abstrato socialmente necessário para produzir a massa de meios de subsistência necessária para a produção e reprodução normais da vida do trabalhador e de sua família em sua totalidade - alimentação, moradia, transporte, vestuário, saúde, educação, lazer etc. Note-se que o valor da força de trabalho não corresponde somente aos meios de subsistência necessários para que o trabalhador realize um determinado trabalho durante o tempo de trabalho que ele vendeu ao capitalista - sua jornada de trabalho -, mas àqueles necessários ao trabalhador e a sua família para a produção normal e digna da vida em sua integralidade durante 24 horas do dia, 365 dias no ano etc. Isso inclui, portanto, uma soma de meios de subsistência para além daqueles necessários ao tempo de trabalho vendido. Por exemplo, a alimentação e o vestuário devem suprir as necessidades não só do "tempo e espaço de trabalho", mas também do "tempo e espaço do não-trabalho", quer dizer, da vida da família do trabalhador, assim como a educação não pode restringir-se à formação ou qualificação para o trabalho, mesmo que tal formação tenha um sentido geral e abrangente, mas abarcar o acesso ao conhecimento e à cultura necessários à vida humana em determinado tipo de sociedade. Em suma, do ponto de vista do capital, a produção e a reprodução da força de trabalho pressupõem a produção, na sua totalidade e em todas as dimensōes, da vida da família do trabalhador, "dentro e fora do trabalho", ou, em outras palavras, a constituição do trabalhador implica a constituição do cidadão. É como ser que vive integralmente na sociedade do capital, satisfazendo as necessidades de todas as dimensões humanas - do estômago à fantasia -, ou seja, é como cidadão e, por conseguinte, consumidor de todos os meios de subsistência necessários à sua vida, que o sujeito produz a força de trabalho, para "depois", na condição de proletário, vendê-la ao seu comprador. Assim, livre e proprietário de uma única mercadoria, sua força de trabalho, que como cidadão a produziu, o vendedor comparece à esfera da circulação para vendê-la ao proprietário do dinheiro e dos meios de produção. 
A esfera da circulação ou do intercâmbio de mercadorias, dentro de cujos limites se movimentam compra e venda de força de trabalho, era de fato um verdadeiro éden dos direitos naturais do homem. O que aqui reina é unicamente Liberdade, Igualdade, Propriedade e Bentham. Liberdade! Pois comprador e vendedor de uma mercadoria, por exemplo, da força de trabalho, são determinados apenas por sua livre-vontade. Contratam como pessoas livres, juridicamente iguais. $\mathrm{O}$ contrato é o resultado final, no qual suas vontades se dão uma expressão jurídica em comum. Igualdade! Pois eles se relacionam um com o outro apenas como possuidores de mercadorias e trocam equivalente por equivalente. Propriedade! Pois cada um dispõe apenas sobre o seu. Bentham! Pois cada um dos dois só cuida de si mesmo. $\mathrm{O}$ único poder que os junta e leva a um relacionamento é o proveito próprio, a vantagem particular, os seus interesses privados. E justamente porque cada um só cuida de si e nenhum do outro, realizam todos, em decorrência de uma harmonia preestabelecida das coisas ou sob os auspícios de uma previdência toda esperta, tão-somente a obra de sua vantagem mútua, do bem comum, do interesse geral.

Ao sair dessa esfera da circulação simples ou da troca de mercadorias, da qual o livre-cambista vulgaris extrai concepções, conceitos e critérios para seu juízo sobre a sociedade do capital e do trabalho assalariado, já se transforma, assim parece, em algo a fisionomia de nossa dramatis personae. $\mathrm{O}$ antigo possuidor de dinheiro marcha adiante como capitalista, segue-o o possuidor de sua força de trabalho como seu trabalhador; um, cheio de importância, sorriso satisfeito e ávido por negócios; o outro, tímido, contrafeito, como alguém que levou a sua própria pele para o mercado e agora não tem mais nada a esperar, exceto o curtume. (Idem, p. 145; grifado por $\mathrm{mim}$ )

A exploração capitalista - o trabalhador que leva sua pele para o curtume - pressupõe, portanto, a produção da vida integral do trabalhador na sociedade do capital, quer dizer, a formação do cidadão. Dilui-se, assim, a linha divisória entre "espaço e tempo de trabalho" e "espaço e tempo fora do trabalho", já que eles se determinam mutuamente e só podem ser espaço e tempo constituídos historicamente na lógica do capital. Estes dois "espaços" se encerram, ou melhor, são expressão fenomênica de um único "espaço", o locus do capital. Não obstante, tudo isso foi resultado de um processo de construção histórica, o processo de consolidação do capital expresso pela subsunção real do trabalho ao capital.

\section{Subsunção formal e subsunção real do trabalho ao capital}

A transição histórica da subsunção formal para a subsunção real do trabalho ao capital, quer dizer, da mais-valia absoluta para a mais- 
valia relativa, ${ }^{2}$ exigia que o capital tivesse o real controle sobre todo o processo de trabalho. Ao longo do desenvolvimento capitalista, tal controle foi se operando, entre outros fatores, por um gradual e efetivo processo de alienação do trabalhador, que perde a propriedade dos meios de produção e, sobretudo, por desdobramento do produto de seu trabalho, dos meios de subsistência. Por essa razão, sem condições de sobrevivência, só lhe resta a propriedade de sua força de trabalho, que, não sendo para ele valor de uso, acaba por aliená-la vendendo-a para o capitalista. É a consolidação do trabalhador como proletário, quer dizer, como vendedor de sua única propriedade, a força de trabalho, para o capitalista.

Uma vez alcançado este estágio de controle histórico, o capital empenha-se na tarefa de diminuir o valor das mercadorias, inclusive o da força de trabalho, o que foi conseguido por um conjunto amplo e articulado de elementos desencadeado por mudanças operadas nos processos de trabalho, principalmente a introdução da maquinaria e da organização industrial, que propiciaram, de um lado, a diminuição ou eliminação dos "poros" da produção e, de outro, a utilização do trabalho feminino e infantil, na medida em que facilitavam os procedimentos de trabalho. De fato, o uso do trabalho feminino e infantil resultou, primeiramente, numa redução do valor da força de trabalho uma vez que o valor desta mercadoria corresponde, como já foi visto, ao quantum de trabalho socialmente necessário para produzir a vida da família do trabalhador. Se apenas um membro da família, o homem, por exemplo, vende sua força de trabalho, o valor da massa de meios de subsistência recai sobre apenas uma unidade de mercadoria a ser vendida. Se a mulher e os filhos passam também a ser vendedores da força de trabalho, o seu valor divide-se por várias unidades, reduzindo assim o valor unitário. ${ }^{3}$ É preciso considerar que, quando vários membros da família se tornam vendedores da força de trabalho, o seu valor absoluto tende a aumentar, pois agora essa família precisará consumir uma quantidade maior de meios de subsistência - por exemplo, transporte para ir ao local de trabalho, que antes era desnecessário para a mulher e os filhos -, mas essa massa maior de valor agora é dividida pelos membros trabalhadores da família, cujo efeito é a diminuição do valor relativo, ou melhor, do valor (individual) da força de trabalho.

Ao mesmo tempo, em razão da permanente concorrência no mercado capitalista, as mudanças operadas nos processos de trabalho, por intermédio da utilização de meios de trabalho com incorporação de tec- 
nologia mais avançada articulada com formas inovadoras de racionalização da produção, propiciaram uma redução no valor das mercadorias, de tal maneira que, quando atinge as cadeias produtivas dos meios de subsistência, resulta também numa diminuição do valor da força de trabalho.

De modo muito resumido, a conexão orgânica dos fenômenos acima relatados criou as condições para a redução do valor da força de trabalho e, por isso, para a produção e exploração da mais-valia relativa. Se a mais-valia absoluta demandava apenas uma subsunção formal do trabalho, já que se tratava apenas de um aumento quantitativo da jornada de trabalho para além do valor da força de trabalho, a mais-valia relativa, diferentemente, exige uma subsunção real do trabalho ao capital, cujas condições básicas são o constante revolucionamento das forças produtivas no conjunto de uma dada sociedade e o controle real do processo de trabalho pelo capital. De fato, Marx afirma que

a produção da mais-valia absoluta gira apenas em torno da duração da jornada de trabalho; a produção da mais-valia relativa revoluciona de alto a baixo os processos técnicos do trabalho e os agrupamentos sociais. Ela supõe portanto um modo de produção especificamente capitalista, que com seus métodos, meios e condições nasce e é formado naturalmente apenas sobre a base da subordinação formal do trabalho ao capital. No lugar da formal surge a subordinação real do trabalho ao capital. (Marx, 1984, p. 106)

Todavia, como o movimento do capital é contraditório, a produção da mais-valia relativa pressupóe a crescente utilização proporcionalmente maior do capital constante (trabalho morto) em relação ao capital variável (trabalho vivo), quer dizer, um aumento da composição orgânica do capital, o que implica, de um lado, a tendencial redução da taxa de lucro e de acumulação de capital e, de outro, uma redução do número relativo de trabalhadores explorados. Isso significa que parte da mercadoria força de trabalho se torna invendável, acarretando uma população proletária excedente e, conseqüentemente, uma diminuição do preço da força de trabalho abaixo de seu valor. A redução do valor da força de trabalho acaba causando, simultânea e contraditoriamente, uma diminuição de seu preço abaixo do valor.

\section{Valor e preço da força de trabalho}

Para que se possa compreender melhor o processo acima descrito, é necessário discorrer um pouco sobre o valor e o preço da força de trabalho. No arcabouço teórico marxiano, valor é uma cate- 
goria analítica relacional, diz respeito à relação de troca entre quantidades de mercadorias distintas, ou melhor, à relação entre proprietários de mercadorias que as levam ao mercado para serem trocadas. No que diz respeito à força de trabalho, os agentes sociais são, por um lado, o produtor, proprietário e vendedor desta mercadoria e, por outro, o seu comprador, proprietário dos meios de produção de capital. Se, nesta relação, o valor da força de trabalho, como o de qualquer outra mercadoria, é determinado pelo quantum de trabalho abstrato socialmente necessário para produzi-la, o que corresponde, no caso específico da força de trabalho, ao quantum de trabalho para produzir os meios de subsistência necessários para produzir e reproduzir a vida da família do trabalhador, e este valor tem uma medida objetiva, dependendo do grau de desenvolvimento das forças produtivas de uma dada sociedade, ${ }^{4} \mathrm{o}$ preço da força de trabalho, embora seja, originalmente, expressão monetária do valor, é determinado imediatamente pelo poder que cada uma das classes detém no "palco" da luta de classes ou, se se quiser, pela correlação de forças entre as classes sociais que realizam o processo de produção, troca e consumo desta mercadoria - capitalistas e proletários. Nesta luta, os contendores apresentam-se munidos de seus respectivos instrumentos de poder e lançam mão das armas mais adequadas e poderosas. Como detém a propriedade dos meios de produção, fontes originárias para a produção da vida humana e, portanto, fundamento maior de poder, a classe capitalista se utiliza dos meios de trabalho como uma de suas principais armas contra os trabalhadores.

Como máquina, o meio de trabalho logo se torna um concorrente do trabalhador. A autovalorização do capital por meio da máquina está na razão direta do número de trabalhadores cujas condições de existência ela destrói. Todo o sistema de produção capitalista repousa no fato de que o trabalhador vende sua força de trabalho como mercadoria. A divisão do trabalho unilateraliza essa força de trabalho em uma habilidade inteiramente particularizada de manejar uma ferramenta parcial. Assim que o manejo da ferramenta passa à máquina, extingue-se, com o valor de uso, o valor de troca da força de trabalho. O trabalhador torna-se invendável, como papel-moeda posto fora de circulação. A parte da classe trabalhadora que a maquinaria transforma em população supérflua, isto é, não mais imediatamente necessária para a autovalorização do capital, sucumbe, por um lado, na luta desigual da velha empresa artesanal e manufatureira contra a mecanizada; inunda, por outro lado, todos os ramos acessíveis da indústria, abarrota o mercado de trabalho e reduz, por isso, o preço da força de trabalho abaixo de seu valor. (Marx, 1984, p. 48; grifado por mim) 
Com uma leve alteração, em vez de se considerar que uma parte supérflua da classe trabalhadora sucumbe na luta desigual da velha empresa artesanal e manufatureira contra a mecanizada, considere-se que tal parte da classe trabalhadora sucumbe na luta mais do que desigual da velha empresa artesanal (urbana e rural), do "setor informal", ou do chamado "terceiro setor" ("empresas" de perfil mais ou menos comunitário, que abarcam um amplo leque de atividades) contra os grandes conglomerados empresariais oligopolistas e transnacionais, o fenômeno relatado por Marx é atual como nunca e, mais do que isso, vem se recrudescendo, tendo em vista que a "maquinaria" utilizada, de base informacional e microeletrônica, é uma arma muitíssimo mais poderosa porque muito mais "dispensadora" da força de trabalho que naquele período, o que implica o aumento do contigente supérfluo de trabalhadores e, por conseguinte, a redução mais acentuada do preço da força de trabalho, muito abaixo de seu valor.

Não obstante, além de ser um instrumento eficaz na redução do preço da força de trabalho, a maquinaria também serve como arma na luta da classe capitalista contra as formas de resistência e organização dos trabalhadores. Apresentando um conjunto de exemplos, Marx afirma que

a maquinaria não atua (...) apenas como concorrente mais poderoso, sempre pronto para tornar trabalhador assalariado "supérfluo". Aberta e tendencialmente, o capital a proclama e maneja como uma potência hostil ao trabalhador. Ela se torna a arma mais poderosa para reprimir as periódicas revoltas operárias, greves etc. (Marx, 1984, p. 51; grifado por mim)

Em suma, as mudanças operadas nos processos de trabalho e o controle que o capital exerce sobre eles produziram uma diminuição do valor e também do preço, abaixo do valor, da força de trabalho e, ao mesmo tempo, serviram como instrumento de neutralização e destruição das formas de resistência e organização dos trabalhadores. A redução do preço da força de trabalho abaixo de seu valor, ocasionada sobretudo pelo aumento do contingente de trabalhadores supérfluos, obrigou, por sua vez, os trabalhadores que ainda conseguiam vender sua força de trabalho a aumentarem sua jornada de trabalho, para tentar compensar a corrosão do preço de sua força de trabalho, o que propiciou a produção e extração da mais-valia absoluta.

A transição histórica da subsunção formal para a subsunção real do trabalho ao capital proporcionou a transição da mais-valia absoluta para a mais-valia relativa. Uma vez consolidada, a subsunção real do trabalho ao capital criou as condições para uma combinação entre a mais- 
valia relativa e a mais-valia absoluta. De fato, na seção IV de $O$ capital, citada anteriormente, Marx não tinha o objetivo de examinar os processos de trabalho "em si", mas analisar a mais-valia relativa - tanto que o título da seção é "A produção da mais-valia relativa" -, ou melhor, como foi possível, por intermédio das mudanças operadas nos processos de trabalho e do controle exercido pelo capital sobre eles, conseguir-se a diminuição do valor da força de trabalho e, por conseguinte, a implementação da mais-valia relativa, o que implicou, contraditoriamente, uma redução de seu preço e, por desdobramento, a implantação da mais-valia absoluta. A produção da mais-valia relativa e sua imbricação com a mais-valia absoluta são, pois, o tema investigado por Marx nessa seção de sua obra.

O fordismo e o controle do processo de trabalho e da vida do trabalhador

O controle sobre o processo de trabalho, elemento determinante de materialização da subsunção real do trabalho ao capital, presente no período da grande indústria, chega a seu auge durante a vigência do taylorismo/fordismo. ${ }^{5}$ Não obstante, nessa fase da acumulação capitalista, o controle e a racionalização do processo de trabalho passam a demandar o controle da vida do trabalhador, pois, como já foi visto, a produção da mercadoria força de trabalho implica a produção da vida humana em sua integralidade. Tal fenômeno foi apropriadamente examinado por Gramsci no seu clássico "Americanismo e Fordismo" (Gramsci, 1984). Para o autor, a implantação do fordismo ("espírito" americano) exigia, além de um novo tipo de Estado, o Estado liberal (idem, ibid., p. 388), um novo tipo de homem, tanto das classes dominantes - que deveriam transitar de ociosos/parasitas para industriais/produtivos - como da classe trabalhadora. Daí a necessidade de se criar uma nova ética, o que explica

o relevo com que os industriais (especialmente Ford) se interessaram pelas relações sexuais dos seus dependentes e pela acomodação de suas famílias; a aparência de "puritanismo" assumida por este interesse (como no caso do proibicionismo) não deve levar a avaliaçôes erradas; a verdade é que não é possível desenvolver o novo tipo de homem solicitado pela racionalização da produção e do trabalho, enquanto o instinto sexual não for absolutamente regulamentado, não for também ele racionalizado. (Idem, ibid., p. 392; grifado por mim)

Tal máxima também era válida para o trabalhador, cuja vida deveria ser controlada em todas as suas dimensóes, até aquelas mais 
recônditas e mais íntimas, como é o caso de sua afetividade e sexualidade, pois o novo industrialismo

exige que o homem-trabalhador não desperdice as suas energias nervosas na procura desordenada e excitante da satisfação sexual ocasional: o operário que vai ao trabalho depois de uma noite de "desvarios" não é um bom trabalhador, a exaltação passional não está de acordo com os movimentos cronometrados dos gestos produtivos ligados aos mais perfeitos processos de automação. Esse conjunto de compressões e coerções diretas e indiretas exercidas sobre a massa produzirá, indubitavelmente, resultados e proporcionará o surgimento de uma nova forma de união sexual, da qual a monogamia e a estabilidade relativa parecem ser o traço característico e fundamental. ${ }^{6}$ (Idem, p. 399; grifado por mim)

Se o período taylorista-fordista traz como "novidade" o controle não só do processo de trabalho, mas também da vida do trabalhador, é possível inferir que o domínio sobre esta última era uma espécie de "extensão" do domínio sobre o primeiro ou, em outras palavras, que o controle do processo de trabalho ainda era determinante em relação ao controle da vida e que, por isso, o controle da vida se dava por causa e por intermédio do controle do processo de trabalho. Tratava-se, assim, de uma subsunção real do trabalho, mas de uma subsunção formal da vida dos trabalhadores ao capital.

\section{$\mathrm{O}$ atual padrão de acumulação e a subsunção real da vida social ao capital}

$\mathrm{O}$ atual padrão de acumulação de capital, que começa a se configurar no início dos anos 70 do século XX, herda do padrão tayloristafordista essa mesma característica, qual seja, a necessidade do duplo controle, do processo de trabalho e da vida do trabalhador. Não obstante, minha hipótese é a de que os pólos da relação se invertem, de tal forma que o controle da vida do trabalhador tenha se tornado determinante em relação ao controle do processo de trabalho e de que tal fenômeno se deveu à própria dinâmica, ao movimento mesmo do capital.

A subsunção formal do trabalho ao capital, expressa pela extração da mais-valia absoluta, por razões históricas, produziu a necessidade e, contraditoriamente, criou as condições para a emergência da mais-valia relativa, que exigia a subsunção real do trabalho ao capital, materializada pelo controle do processo de trabalho, que se logrou no período da grande indústria, e que resultou, por razões apontadas anterior- 
mente, na combinação das duas formas de extração de mais-valia. O controle do processo de trabalho, por sua vez, demandou um controle também da vida do trabalhador, de tal maneira que o capital atingiu o ápice, a consolidação da subsunção real do trabalho ao capital, na fase taylorista-fordista, situação que propiciou, pelo menos no centro do sistema capitalista, a preponderância da mais-valia relativa em relação à mais-valia absoluta. Isso significa que nos países centrais do capitalismo foi possível, por um certo tempo, que o preço da força de trabalho dos trabalhadores originários desses mesmos países se mantivesse num patamar de relativo equilíbrio com o valor da força de trabalho, permitindo assim uma produção normal da vida daqueles trabalhadores, o que criou o terreno propício para o surgimento da alternativa socialdemocrata concretizada na "concertação" social entre Estado, trabalhadores e capitalistas, que resultou no Estado do Bem-Estar Social. Embora tenha obedecido a razões fundamentalmente políticas, dado o quadro histórico da época, a emergência e consolidação do Welfare State, por um interregno, só foi possível em razão, por um lado, desse elemento determinante da base material e, por outro, da "exportação", para a periferia do sistema, das características de agudização das contradições da acumulação de capital, sobretudo a redução do preço da força de trabalho acentuadamente abaixo de seu valor, o que dificultou ou inviabilizou a implantação do Estado do Bem-Estar Social nessa parte do sistema.

O controle da vida do trabalhador, que no modelo keynesianofordista era um desdobramento do controle do processo de trabalho, chega a seu patamar de consolidação e torna-se determinante em relação ao controle do processo de trabalho no atual padrão de acumulação de capital. Por causa, sobretudo, da concorrência intercapitalista, um dos componentes decisivos do movimento do capital, o fantástico desenvolvimento das forças produtivas das últimas décadas, em velocidade e grau jamais assistidos, possibilitou a produção de quantidades imensuráveis de mercadorias com um reduzido quantum de valor (trabalho abstrato), o que proporcionou uma substancial diminuição do valor das mercadorias em geral, inclusive o da força de trabalho, mas causou, contraditoriamente, dois efeitos. O primeiro, um incremento brutal, sem precedentes na história, de força de trabalho supérflua, formada tanto pelo contingente de trabalhadores que foi desempregado como por aquele que jamais será empregado, fenômeno que muitos autores chamam de "desemprego estrutural"; e o segundo, uma acentuada diminuição da taxa de lucro e, conseqüentemente, da taxa de acumulação, tendo em vista o considerável e necessário aumento da composi- 
ção orgânica do capital, quer dizer, o investimento proporcionalmente maior em capital constante com relação ao capital variável. Creio que seja possível inferir que, contemporaneamente, este último problema deva estar se multiplicando exponencialmente, já que os meios e instrumentos de trabalho utilizados pelas empresas capitalistas, de base microeletrônica, prescindem cada vez mais da força de trabalho, única e exclusiva mercadoria que, na condição de valor de uso do capitalista, é capaz de produzir valor, portanto mais-valia e portanto capital.

A combinação desses dois fatores vem causando uma substancial diminuição do preço da força de trabalho, o que é, por sua vez, uma necessidade inelutável do capital. Contudo, tal é o grau de agudização das contradições da acumulação que a redução do preço da força de trabalho abaixo do seu valor, diferentemente do que ocorreu no passado recente, vem se generalizando e atingindo gradativamente também os trabalhadores originários dos países centrais do sistema capitalista, o que tem provocado a necessidade de aumento na jornada de trabalho por parte dos trabalhadores que ainda têm o "privilégio" de vender sua força de trabalho e, portanto, a produção e extração da mais-valia absoluta. Além do empenho de alguns países no sentido de ampliar, oficial e formalmente, a jornada de trabalho, é preciso ressaltar, contudo, que a produção da mais-valia absoluta pode se realizar seja pelo aumento do tempo efetivo de trabalho vendido ao capital, ${ }^{7}$ que pode se representar por um ou diversos capitalistas - o trabalhador que é obrigado a trabalhar em várias empresas -, mesmo que tal fator não apareça nos dados e em estatísticas oficiais, seja por uma forma mais sutil e, ao mesmo tempo, muito mais eficaz, que é o aumento da intensidade, do ritmo e da velocidade do trabalho acima de condiçôes normais; ${ }^{8}$ o que é muito distinto do aumento da produtividade, que pressupõe um incremento da produção de mercadorias com um quantum igual ou menor de valor em condiçôes humanas e sociais normais.

O processo que propiciou a diminuição do valor da força de trabalho e, portanto, a produção e extração da mais-valia relativa, criou, ao mesmo tempo e contraditoriamente, a necessidade e as condições de redução do preço da força de trabalho abaixo de seu valor e, por conseguinte, da produção e extração da mais-valia absoluta. A utilização em larga escala, na atualidade, do trabalho feminino e também do trabalho infantil, do imigrante etc., além de outras táticas como a terceirização, tudo isso faz parte dessa mesma lógica. Entretanto, no atual padrão de acumulação, pelos motivos apontados anteriormente, há uma necessidade 
e, por essa razão, uma tendência de diminuição mais acentuada do preço da força de trabalho em relação à redução de seu valor, o que significa uma tendência de preponderância da mais-valia absoluta em relação à mais-valia relativa, cujo resultado é o recrudescimento e a generalização da degradação do trabalho.

Marca distintiva do atual padrão de acumulação é, pois, uma tendência de generalização da preponderância da mais-valia absoluta em relação à mais-valia relativa, elemento determinante da base material que explica as dificuldades de "concertação" social e a crise do Estado do Bem-Estar Social.

Além disso, a agudização das contradições do movimento do capital, elencadas ao longo do texto, vem exigindo que o Estado capitalista intervenha cada vez mais no processo de produção e acumulação de capital, destinando-lhe vultosos recursos, na tentativa de salvaguardar a reprodução capitalista. Isso pode ser evidenciado por alguns exemplos. Primeiramente o financiamento subsidiado e, em alguns casos, a doação parcial ou total - por intermédio da construção de infra-estrutura ou da redução e até isenção de impostos, entre outros mecanismos - oferecidos pelo Estado aos capitais privados, que acaba por responder, dessa forma, pelo investimento em parte do capital constante. O resultado disso é uma atenuação, mesmo que temporária, da tendência de aumento da composição orgânica do capital e, por conseguinte, de diminuição da taxa de lucro, o que se constitui numa medida preventiva, ainda que precária, em relação à eclosão das crises capitalistas.

Em segundo lugar, a necessidade de injeção de volumosos recursos estatais por ocasião das crises e de seus desdobramentos - que ocorrem, inevitavelmente, como conseqüência do conjunto de contradições da acumulação - com o escopo não só de prestar socorro, mas, sobretudo, de buscar a manutenção da reprodução do capital.

A necessidade de uma maciça e crescente intervenção do Estado na economia, bem como a utilização também ascendente de recursos para realização de suas outras funções precípuas, inclusive as de coerção e repressão, vêm obrigando o Estado a se desvencilhar de tarefas que a ele foram atribuídas por razões histórico-políticas, a saber, as chamadas políticas sociais - educação, saúde, previdência e seguridade social etc. Trata-se da constituição daquilo que vem sendo denominado de "Estado mínimo". Contudo, é preciso salientar que este é apenas um dos "lados da moeda", já que o "outro lado" expressa o "Estado máximo", ou seja, ele é "mínimo e máximo" ao mesmo tempo. Para ser "máximo" na sua função determinante de salvaguardar a reprodução do capital no seu 
movimento contraditório, o Estado vê-se obrigado a ser "mínimo" no atendimento às políticas sociais.

Tendo em vista, sobretudo, os dois fatores apontados anteriormente, quais sejam, o solapamento das condições de produção e reprodução normais da força de trabalho, o que tem gerado uma crescente e generalizada degradação do trabalho, e a necessidade de um gradual desembaraçamento do Estado em relação às políticas sociais, o atual padrão de acumulação e o Welfare State são, no limite, inconciliáveis.

Além disso, desde o período da grande indústria, o capital, pela própria lógica de seu movimento, vem se ampliando, estendendo seus tentáculos não só por todos os quadrantes do mundo, cuja expressão mais significativa é o advento do imperialismo, mas também por todas as atividades econômicas e ramos da produção. Da atividade fabril, que era, no século XIX, praticamente o único espaço econômico onde se estabelecia a relação especificamente capitalista e, por conseguinte, a produção da mais-valia, o capital penetrou e dominou quase todos os outros setores e atividades: agricultura, transportes, pesquisa e tecnologia, comunicações, saúde, educação, serviços, cultura, entretenimento e esporte etc., sem contar com um dos ramos mais cobiçados e lucrativos, a saber, a indústria bélica. $\mathrm{Na}$ medida de sua penetração, em tais atividades econômicas passa a prevalecer a relação capitalista e, portanto, a produção de mais-valia e, conseqüentemente, de capital.

Mesmo na condição de determinante, o mercado especificamente capitalista, cuja característica essencial é a relação de produção capitalista intermediada pela troca da força de trabalho, era quase que circunscrito à atividade fabril na época de Marx, e convivia tanto com um amplo mercado não-capitalista, responsável pela produção e troca de diversas mercadorias e que estabelecia as mais variadas relaçôes sociais de produção, como com um conjunto de setores econômicos, relativamente autônomos, produtores de valores de uso. No atual padrão de acumulação, diferentemente, o mercado capitalista ampliou-se sobremaneira em relação ao mercado geral e açambarcou quase todas as outras atividades econômicas originalmente não-capitalistas, o que pode ser evidenciado pela presença dos onipotentes e onipresentes oligopólios transnacionais. Embora o mercado não-capitalista sobreviva - e vai sempre sobreviver no capitalismo -, seu espaço e possibilidade de ação são cíclicos e tendem a se contrair, restringindo-se a atividades para as quais o capital tem pouco ou nenhum interesse.

Contudo, a ampliação do mercado capitalista foi e tem sido acompanhada, simultânea e contraditoriamente, por uma contração 
relativa do mercado de trabalho capitalista, na medida em que, conforme visto anteriormente, o desenvolvimento das forças produtivas sob a forma capitalista causa a diminuição relativa da utilização da força de trabalho, ou seja, reduz relativamente o número de trabalhadores requeridos e explorados pelo capital. O mercado capitalista, pois, amplia-se reduzindo relativamente a utilização da força de trabalho. O resultado da articulação contraditória desses dois fenômenos é, de um lado, o incremento sistemático e "estrutural" do desemprego, sobretudo no período recente, dada a velocidade do desenvolvimento das forças produtivas, e, de outro, a redução e, em muitos casos, a eliminação de alternativas de produção da vida, quer dizer, de sobrevivência - além da venda da mercadoria força de trabalho -, seja pela produção e venda de outras mercadorias, ou pela produção de valores de uso, tal o grau de abrangência, controle, concentração e centralização do capital. ${ }^{9}$

Domínio sobre praticamente todas as atividades humanas, sobre a produção social da vida e redução generalizada do preço da força de trabalho combinada com um imenso (e insolúvel) contingente supérfluo de trabalhadores, eis os ingredientes fundamentais para o controle do capital sobre a vida dos trabalhadores. A subsunção real do trabalho e a subsunção formal da vida dos trabalhadores ao capital transformam-se, na contemporaneidade, em subsunção real da vida dos trabalhadores ao capital. Mais do que isso, tendo em vista o controle do capital sobre toda a vida social, transformam-se em subsunção real da vida social ao capital. Dessa forma, o controle do processo de trabalho realiza-se por intermédio do controle da vida social, o primeiro subordinando-se ao segundo, de tal maneira que o capital tende a prescindir de um controle mais sistemático e hostil sobre os trabalhadores no âmbito dos processos de trabalho, dispensando, inclusive, os empregados que desempenham esse tipo de função, tendo em vista o autocontrole exercido pelos próprios trabalhadores. ${ }^{10}$ Tudo isso significa, portanto, o coroamento da articulação orgânica do "espaço do trabalho" e do "espaço fora do trabalho" num único e mesmo "espaço", o locus do capital.

Se, como foi visto, a transição da subsunção formal para a subsunção real do trabalho requereu o controle do capital sobre os processos de trabalho, que se logrou a partir de um processo histórico de alienação do trabalhador, a passagem da subsunção real do trabalho à subsunção real da vida social ao capital vem se realizando por intermédio do controle que o capital tem exercido sobre praticamente todas as atividades de produção e reprodução da vida humana em sociedade, o que vem 
reduzindo ou eliminando formas alternativas de sobrevivência e cuja implicação tem sido a agudização das contradições da acumulação capitalista e o agravamento da degradação do trabalho. Como desdobramento, assim como o modelo keynesiano-fordista demandou um novo tipo de Estado e um novo tipo de homem, o atual padrão de acumulação exige, por sua vez, um novo tipo de Estado, nos moldes do chamado "neoliberalismo" e um novo tipo de homem, integrado na lógica societal do capital. Trata-se de um sujeito que não apenas "veste a camisa da empresa" mas, acima de tudo, um ser humano que, premido pelas condiçôes materiais, "veste a camisa do capital".

A transição histórica da subsunção formal para a subsunção real do trabalho ao capital e desta para a subsunção real da vida social ao capital se iniciou, em articulação com outros fatores, por meio das mudanças e do controle do processo de trabalho e da utilização capitalista da maquinaria, o que desencadeou, como vimos, um conjunto de contradições. Não obstante,

as contradições e os antagonismos inseparáveis da utilização capitalista da maquinaria não existem porque decorrem da própria maquinaria, mas de sua utilização capitalista! Já que, portanto, considerada em si, a maquinaria encurta o tempo de trabalho, enquanto utilizada como capital aumenta a jornada de trabalho; em si, facilita o trabalho, utilizada como capital aumenta sua intensidade; em si, é uma vitória do homem sobre a força da Natureza, utilizada como capital submete o homem por meio da força da Natureza; em si, aumenta a riqueza do produtor, utilizada como capital, pauperiza-o etc. (Marx, 1984, p. 56-57; grifado por mim)

Para que os meios de produção da vida humana deixem de ser elementos de degradação, aviltamento e destruição do gênero humano, e se tornem instrumentos de sua emancipação, faz-se mister, portanto, divorciá-los de sua utilização capitalista, o que implica necessariamente uma revolução da ordem societal capitalista e a construção de uma sociedade para além do capital.

Recebido em fevereiro de 2002 e aprovado em fevereiro de 2003.

\section{Notas}

1. Vide, entre outros, Antunes (1995 e 1999), Burawoy (1990), Dias et al. (1996), Harvey (1993), Katz \& Coggiola (1995) e Teixeira (1996). 
2. Não se trata aqui de uma ordem cronológica, já que, como veremos adiante, há uma imbricação orgânica entre as duas formas de extração da mais-valia; uma implica a outra e vice-versa. A esse respeito vide, sobretudo, o capítulo XIV de O Capital (Marx, 1984).

3. Sobre essa questão, Marx assevera que "o trabalhador vendia anteriormente sua própria força de trabalho, da qual dispunha como pessoa formalmente livre. Agora vende mulher e filho. Torna-se mercador de escravos" (Marx, 1984, p. 23).

4. Convém lembrar que o valor das mercadorias se altera na relação inversa do desenvolvimento das forças produtivas. Quanto mais desenvolvidas estas últimas, menor o valor das mercadorias e vice-versa. Por isso, há uma tendência de diminuição do valor das mercadorias, inclusive do da força de trabalho, propiciando a extração da mais-valia relativa, conforme já visto anteriormente.

5. A respeito deste assunto vide, entre outros, Braverman (1987).

6. Gramsci também relata a luta desenvolvida contra o uso do álcool, "o mais perigoso agente de destruição das forças de trabalho", que passa a se tornar função do Estado. Para ele, é possível que "outras lutas 'puritanas' passem a ser funçôes do Estado, se a iniciativa privada dos industriais parecer insuficiente, ou se se desencadear uma crise de moralidade bastante profunda entre as massas trabalhadoras, o que poderia ocorrer em conseqüência de uma longa e ampla crise de desemprego" (Gramsci, 1984, p. 398). Em contrapartida, é possível considerar que, talvez, o exemplo peculiar de controle sobre a vida do trabalhador tenha sido a constituição das "vilas operárias" em torno das fábricas, que se espalharam por todos os cantos do mundo onde o capital penetrou.

7. Embora não se possa comprovar formalmente, uma vez que se trata de uma situação totalmente ilegal, um dos fenômenos mais recorrentes em muitos países, como é o caso do Brasil, não é o aumento do tempo de trabalho vendido, mas doado ao capital, já que muitas empresas têm obrigado seus respectivos trabalhadores a fazerem horas-extras, sem as pagarem, total ou parcialmente.

8. Antunes, por exemplo, analisa a intensificação das condições de exploração da força de trabalho sob o toyotismo (cf. Antunes, 1999, p. 53) e, citando o Japan Press Weekly, lembra que a recente proposta elaborada pelo governo japonês "é de aumentar o limite da jornada de trabalho (de 9 para 10 horas) e a jornada semanal de trabalho (de 48 para 52 horas)" (idem, p. 56).

9. Na sociedade da "livre-iniciativa", como é o capitalismo, qualquer pessoa pode, a qualquer momento, "abrir seu próprio negócio", como uma loja de doces, uma confecção de camisetas ou um carrinho de hot-dog etc. A sua sobrevivência, contudo, limita-se ao surgimento e à concorrência de alguma grande empresa capitalista. Que lanchonete sobrevive quando tem de competir com um "McDonald's", por exemplo?

10. É possível considerar que não exista instrumento mais eficaz de controle ou autocontrole dos trabalhadores que "o medo do desemprego numa sociedade de desempregados".

\title{
Referências bibliográficas
}

\begin{abstract}
ANTUNES, R. Adeus ao trabalho? Ensaio sobre as metamorfoses e a centralidade do mundo do trabalho. São Paulo: Cortez; Campinas: UNICAMP, 1995.
\end{abstract}

ANTUNES, R. Os sentidos do trabalho. Ensaio sobre a afirmação e a
negação do trabalho. São Paulo: Boitempo, 1999.

Educ. Soc., Campinas, vol. 24, n. 82, p. 159-178, abril 2003

Disponível em <http://www.cedes.unicamp.br> 
ARRIGHI, G. Trabalhadores do mundo no final do século. Praga: revista de estudos marxistas, São Paulo, n. 1, p. 27-43, 1996.

BRAVERMAN, H. Trabalho e capital monopolista: a degradação do trabalho no século XX. 3. ed. Rio de Janeiro: Guanabara, 1987.

BURAWOY, M. A transformação dos regimes fabris no capitalismo avançado. Revista Brasileira de Ciências Sociais, São Paulo, v. 5, n. 13, p. 29-50, 1990.

CATANI, A.D. Processo de trabalho e novas tecnologias. Porto Alegre: UFRGS, 1995.

CATANI, A.D. (Org.). Trabalho e tecnologia: dicionário crítico. Petrópolis: Vozes; Porto Alegre: UfRGS, 1997.

CHESNAIS, F. Novo capitalismo intensifica velhas formas de exploração. Folha de S. Paulo, São Paulo, 2 nov. 1997. Caderno Especial, p. 4.

COGGIOLA, O. A crise estrutural do capital. Quinzena, São Paulo, n. 262, 15 jan. 1998.

DIAS, E. et al. A ofensiva neoliberal, reestruturação produtiva e luta de classes. Brasília, DF: Sindicato dos Eletricitários, 1996.

FRIGOTTO, G. Educação, crise do trabalho assalariado e do desenvolvimento: teorias em conflito. In: FrigotTo, G. (Org.). Educação e crise do trabalho: perspectivas de final de século. Petrópolis: Vozes, 1998.

GLOBALIZAÇÃO aprofunda o abismo entre ricos e pobres. Folha de S. Paulo, São Paulo, 2 nov. 1997. Caderno Especial, p. 12.

GRAMSCI, A. Americanismo e Fordismo. In: GRAMSCI, A. Maquiavel, a política e o Estado moderno. 5. ed. Rio de Janeiro: Civilização Brasileira, 1984.

HARVEY, D. A condição pós-moderna. São Paulo: Loyola, 1993.

KATZ, C.; COGGIOLA, O. Neoliberalismo ou crise do capital? São Paulo: Xamã, 1995.

KATZ, C.; BRAGA, R.; COGGIOLA, O. Novas tecnologias: crítica da atual reestruturação produtiva. São Paulo: Xamã, 1995.

KONIG, H. A crise da sociedade do trabalho e o futuro do trabalho: crítica de um debate atual. In: MARKerT, W. (Org.). Teorias de educação do iluminismo, conceitos de trabalho e sujeito. Rio de Janeiro: Tempo Brasileiro, 1994. 
KURZ, R. O colapso da modernização. São Paulo: Paz \& Terra, 1993. MANDEL, E. A crise do capital: os fatos e sua interpretação marxista. Campinas: UNICAMP, 1990.

MARX, K. O método da economia política. In: MARX, K. Manuscritos econômico-filosóficos e outros textos escolhidos. São Paulo: Abril Cultural, 1974.

MARX, K. O capital. São Paulo: Abril Cultural, 1983. v.1. t.1.

MARX, K. O capital. São Paulo: Abril Cultural, 1984. v.1. t.2.

MARX, K. Capítulo VI inédito de $O$ capital. São Paulo: Moraes, 1985.

MEIKSINS, P. Trabalho e capital monopolista para os anos 90: uma resenha crítica do debate sobre o processo de trabalho. Critica Marxista, São Paulo, v. 1, n. 3, p. 106-117, 1996.

MÉSZAROS, I. Produção destrutiva e estado capitalista. São Paulo: Ensaio, 1989.

NAPOLEONI, C. Liçôes sobre o capitulo sexto (inédito) de Marx. São Paulo: Ciências Humanas, 1981.

NETTO, J.P. Prólogo: elementos para uma leitura crítica do Manifesto Comunista. In: Marx, K.; Engels, F. Manifesto do Partido Comunista. São Paulo: Cortez, 1998.

RUBIN, I.I. A teoria marxista do valor. São Paulo: Polis, 1987.

TEIXEIRA, F.J.S. Pensando com Marx: uma leitura crítico-comentada de $O$ capital. São Paulo: Ensaio, 1995.

TEIXEIRA, F.J.S. (Org). Neoliberalismo e reestruturação produtiva. São Paulo: Cortez; Fortaleza: UECE, 1996.

TUMOLO, P.S. Habermas versus Marx: o marxismo na berlinda? Praxis, Belo Horizonte, v. 4, n. 10, out.1997/fev.1998. Projeto Joaquim de Oliveira.

TUMOLO, P.S. Reestruturação produtiva no Brasil: um balanço crítico introdutório da produção bibliográfica. Educação \& Sociedade, Campinas, n. 77, p. 71-99, 2001.

TUMOLO, P.S. Da contestação à conformação. A formação sindical da CUT e a reestruturação capitalista. Campinas: Unicamp, 2002. 